\title{
NITRIFICATION INHIBITION USING BENZOTRIAZOLES
}

\author{
${ }^{1}$ T. Callender and ${ }^{2}$ L. C. Davis \\ ${ }^{1}$ Wamego High School, Wamego KS 66547. \\ 2 Department of Biochemistry, Willard Hall, Kansas State University, Manhattan, KS 66506; \\ Phone (785)532-6124; Fax: (785)532-7278.
}

\begin{abstract}
The common corrosion inhibitor, $1 \mathrm{H}$-benzotriazole (Bz), found as a component of glycol-based aircraft deicers, and its derivatives, such as 5-chloro-1H-benzotriazole (CBz), 1-hydroxybenzotriazole (HBz), and 5methyl-1H-benzotriazole (MBz), are all potential nitrification inhibitors (McCarty and Bremner, 1989). The inhibitory effect of benzotriazoles on the nitrification of urea- $\mathrm{N}$ fertilizer in agricultural soils was examined over a four-week period. At $10 \mathrm{mg} / \mathrm{kg}$, all compounds tested, except $\mathrm{HBz}$, have the ability to inhibit the nitrification of urea-N fertilizer effectively. Their inhibitory capabilities depend on the structural components of the soil, particularly organic matter (O.M.). In the soil with the largest percent of O.M. (2.3\%), inhibition by all the benzotriazole derivatives was considerably decreased. In the soil with least O.M. (0.3\%), even HBz, the poorest of the inhibitors, showed signs of inhibition. For Bz, MBz, and CBz in the range of $90 \%$, inhibition was observed in the soil with the lowest O.M. content during a four-week treatment period. On a mass basis Bz had the greatest inhibitory effect followed by $\mathrm{MBz}$ and $\mathrm{CBz}$, whereas $\mathrm{HBz}$ showed little inhibition of the nitrification of urea-N in soils with $>0.5 \%$ O.M. On a molar concentration basis, there would be little variation in inhibitory potency for $\mathrm{MBz}, \mathrm{CBz}$, and Bz. It was concluded that all three are effective nitrification inhibitors with urea-N fertilizer. Incorporation of benzotriazoles as inhibitors could help economize $\mathrm{N}$ fertilizers by helping prevent nitrate leaching and denitrification. However, the environmental fate of these compounds has not been determined, and they are toxic to plants and other organisms at higher concentrations $(10-100 \mathrm{mg} / \mathrm{L})$. Inhibition of nitrification is undesirable when high levels of ammonia are to be removed by combined nitrification and denitrification, as occurs in some sewage treatment processes.
\end{abstract}

Key words: nitrification, benzotriazoles, deicing fluids, corrosion inhibitors, methylbenzotriazole, ADFs

\section{INTRODUCTION}

Benzotriazoles have high stabilities both at high temperatures and in presence of ultra violet (UV) light (USEPA, 1977). They have a wide range of industrial uses. Since they complex strongly with some metals, they are commonly used as corrosion inhibitors in glycol-based aircraft deicing fluids (ADFs). The majority of simple benzotriazoles currently produced go into such anticorrosion applications. The structure and ring numbering of $1 \mathrm{H}$-benzotriazole is as shown in Figure 1. Common derivatives include methyl groups at the 4 or 5 position, chlorine at the 5 position, or replacement of the $\mathrm{H}$ by $\mathrm{OH}$ at the 1 position. Typical applications include the protection of coppercontaining parts (for which benzotriazole excels), by inclusion of benzotriazoles in automobile antifreeze solutions, in recirculating water systems such as power plant and commercial air-conditioning cooling systems, and in coatings for protection of copper alloys in architectural and decorative applications. More complex nonpolar derivatives (generally at the $2 \mathrm{~N}$ position) are also used widely to stabilize plastics and similar materials against the decomposition that would otherwise take 


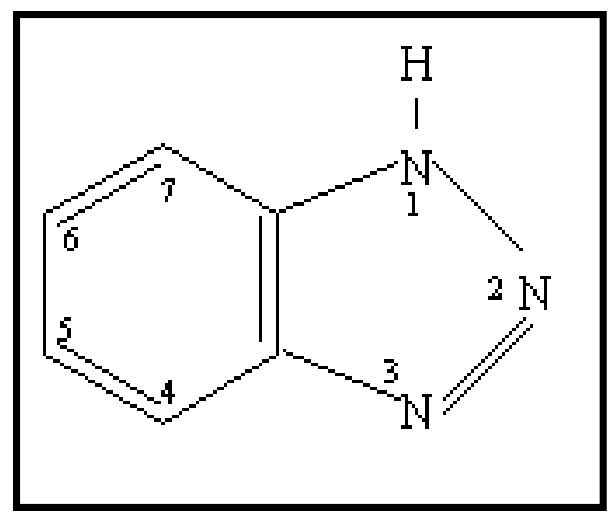

Figure 1. Structure of benzotriazole, showing ring numbering.

place upon exposure of these materials to UV radiation. Metal chelation ability (to silver) accounts for their use in photography, mainly as an antifogging constituent of films (USEPA, 1977). Recently, 1hydroxybenzotriazole has been proposed to serve as a mediator of laccase action in pulp bleaching to decrease the amount of corrosive bleaching chemicals in the paper-making process (Call and Mucke, 1997).

Human safety is a concern with all various industries involved with the consumption of benzotriazoles (USEPA, 1977). These compounds also may present an environmental problem due to their appreciable water solubility, persistence under environmental conditions, and toxicity to microorganisms and plants (Pillard, 1995; Cornell et al., 2000). Until now, reports have not revealed ways for treating waste streams containing benzotriazoles by conventional methods due to the lack of microorganisms that can degrade most benzotriazoles (Rollinson and Callely, 1986). A non-conventional system for treating benzotriazole-contaminated water, such as land application using phytoremediation, could have significant merit (Castro et al., 2001).

In modern agro-ecosystems where large quantities of $\mathrm{N}$ fertilizers are used continuously, the efficiency of their use may be low and may result in environmental pollution (Puttanna et al., 2001a,b). Much fertilizer $\mathrm{N}$ applied to soils is in the form of ammonium or ammonium-producing compounds such as urea. Ammonium is usually oxidized quite rapidly to nitrate by nitrifying microorganisms in soil. The nitrate thus produced is susceptible to loss by leaching and denitrification, and there is international concern about pollution of ground and surface waters by fertilizer-derived nitrate. This concern has stimulated research to find compounds that will effectively inhibit nitrification of fertilizer $\mathrm{N}$ when 
applied to soils in conjunction with $\mathrm{N}$ fertilizers. Numerous compounds have been patented or proposed for this purpose (Bundy and Bremner, 1973; McCarty \& Bremner, 1989; McCarty, 1999; Puttanna et al., 1999, 2001a,b). Efficient N management techniques such as the use of nitrification inhibitors may help conserve $\mathrm{N}$ fertilizers in situations where leaching or denitrification is a problem. McCarty and Bremner (1989) first reported that benzotriazole was a nitrification inhibitor while Puttanna et al. (1999, 2001a,b) have evaluated its effectiveness under tropical conditions and demonstrated its efficacy in a field study. Puttanna et al. proposed that benzotriazoles might be good candidates for agricultural use because they have been in use for many years in other applications. They assumed that common use implies environmental safety.

By studying the benzotriazole derivatives as nitrification inhibitors in agricultural soils, we may obtain a better understanding of two environmental concerns: nitrate loss and benzotriazole fate and effect in the environment. We may obtain insight into the underlying assumption of Puttanna et al. (1999) that extensive use implies safety.

\section{MATERIALS AND METHODS}

Soils used for all experiments reported here were surface soils obtained from agricultural sites between Wamego and Manhattan, Kans. Properties are summarized in Table 1. The "river bank" soil was from a field along the Kansas River, while the "Manhattan pile” was topsoil that had been stored as a large pile. The samples designated “north” and “south” were from arable fields north and south of the river. Before use, each sample was air-dried and crushed to pass through a U.S. Standard Sieve (No. 8, 2380 microns, 0.0937 inches). Samples of the soils were then sent to the Kansas State Soil Testing Lab to be tested for $\mathrm{pH}$, sand \%, silt \%, clay \%, and organic matter \% (O.M.) (Table 1).

The benzotriazole derivatives used in the inhibition test were $1 \mathrm{H}$-benzotriazole, 1-hydroxybenzotriazole, 5-methyl-1H-benzotriazole, and 5-chloro-1H-benzotriazole. All were purchased from Sigma-Aldrich and used as purchased by preparing stock water solutions of 0.5 to $2 \mathrm{~g} / \mathrm{L}$, which were diluted as needed for soil treatment. Urea and potassium nitrate were from Fisher Scientific. 
The procedure used to determine effects of test compounds on nitrification in soil was as follows: 100 grams of selected soil sample was placed in an amber glass jar ( 0.5-0.8 L) and treated with enough solution to bring the soil to $60 \%$ field capacity. (The appropriate amount of water for each soil type was determined in a separate preliminary experiment.) The test solutions used consisted of deionized water, $10 \mu \mathrm{g} / \mathrm{g}$ soil of a specific test compound, and 100 $\mu \mathrm{g} / \mathrm{g}$ of $\mathrm{N}$ as $\mathrm{NH}_{2} \mathrm{CONH}_{2}$ (urea-N). Controls were also made for all the soils consisting of an $\mathrm{H}_{2} \mathrm{O}$ control (soils treated to $60 \%$ field capacity with a water solution only), a urea-N control (soils treated with $100 \mu \mathrm{g} / \mathrm{g}$ of soil of urea-N but omitting nitrification inhibitor), and a $\mathrm{KNO}_{3}$ control (soils treated with $100 \mu \mathrm{g} / \mathrm{g}$ of soil of $\mathrm{N}$ as $\mathrm{KNO}_{3}$ to represent $100 \%$ nitrification of $\mathrm{N}$ ). The jars were kept covered but unsealed to incubate at room temperature (about 22 degrees $\mathrm{C}$ ).

Soils were analyzed for $\mathrm{NO}_{3}-\mathrm{N}$ every week for a maximum of four weeks. Samples were analyzed using a Hach DR/2000 (direct reading spectrophotometer), following the method outlined by the manufacturer. Precisely weighed samples of soil (6+ g), containing a known proportion of water, were treated with exactly 7.0 volumes $(42+\mathrm{mL})$ of a solution of $0.3 \%$ calcium sulfate $\left(\mathrm{CaSO}_{4}\right)$ to flocculate soil to provide clear samples for $\mathrm{NO}_{3}-\mathrm{N}$ testing. After centrifugation, 25.0 $\mathrm{mL}$ of the clear supernatant was used for analysis. The Hach reagents were added, mixed for a controlled time of $1 \mathrm{~min}$, and read after a fixed time. From the absorbance values obtained with a standard solution of nitrate $(5 \mathrm{mg} / \mathrm{L}=0.132)$, concentrations of the unknown solutions were determined. They were multiplied by 7 to convert them to $\mathrm{mg} / \mathrm{kg}$ of fresh soil. The apparent absorbance

Table 1. Soil analysis.

\begin{tabular}{|l|c|c|c|c|c|}
\hline Sample ID & $\mathbf{p H}$ & Sand \% & Silt \% & Clay \% & $\begin{array}{c}\text { Organic } \\
\text { Matter \% }\end{array}$ \\
\hline River Bank & 7.6 & 54 & 32 & 14 & 0.3 \\
\hline $\begin{array}{l}\text { Manhattan } \\
\text { Pile }\end{array}$ & 6.2 & 22 & 45 & 33 & 2.1 \\
\hline North & 7.4 & 44 & 42 & 14 & 2.3 \\
\hline South & 7.5 & 26 & 58 & 16 & 1.6 \\
\hline
\end{tabular}


values displayed in figures are those that would be obtained without dilution, that is, $7 \mathrm{x}$ the actually measured value. The input amount of urea or nitrate was calculated to give $100 \mathrm{mg} / \mathrm{kg} \mathrm{N}$ in addition to the background amount present in the soil. The percent nitrification for each sample was calculated from (C-T)/Cx100, where $\mathrm{T}$ is the actual absorbance level of the nitrification of urea-N in soil samples treated with the test compounds and $\mathrm{C}$ is the actual absorbance level from the nitrification of urea-N controls. No correction was made for the initial amount of nitrate present in each soil. Thus the relative extent of inhibition was underestimated. An alternative calculation could use the initial amount of nitrate present in the soil, giving $\Delta \mathrm{C}$ and $\Delta \mathrm{T}$ values. As shown below, the nitrate level in untreated (water control) soils changed over time for some soils so that assumptions about inhibition of that endogenous nitrification would be needed to get a more precise estimate.

\section{DISCUSSION AND ANALYSIS OF RESULTS}

Figures 2 through 5 show results for the indicated soil types as a function of time of incubation. It is readily apparent from the water controls that the level of endogenous nitrate varies widely between soils. The good agreement over time in the measured nitrate from the potassium nitratetreated soils indicates the reproducibility of the analytical method. For some soils, there is apparently an increase in endogenous nitrate, presumably due to nitrification of organic matter. Different soils show markedly different rates of nitrification of added urea. The ability of benzotriazoles to inhibit nitrification also differs for the different soils, mainly as a function of the organic matter content of the soil but also due to other conditions such as $\mathrm{pH}$ (compare the Manhattan pile soil to the north or south, which have similar levels of O.M.) (Table 1).

Table 2 provides a summary of results expressed as relative inhibition of nitrification with various soil types and times of incubation. For each time interval, the extent of nitrate formation by urea alone was determined and set equal to zero percent inhibition. The different inhibitor treatments were then compared to that value. The extent of nitrification of urea differed considerably between soil types. It was found that the north soil was the first to completely nitrify the urea. By the first week of analysis, the concentration of nitrate- $\mathrm{N}$ in the urea-N-only control was almost the same as the potassium nitrate control, which represents the full nitrification of urea- $\mathrm{N}$. The nitrate control had 
a concentration of $176 \mathrm{mg} / \mathrm{L}$, whereas the urea-N control gave a concentration of $170 \mathrm{mg} / \mathrm{L}$, only a 3.5\% difference (see Figure 2). In treatments with the benzotriazole derivatives (Bz, HBz, MBz, and $\mathrm{CBz}$ ), there was 28-41\% less nitrate after the first week in the north soil. Even the 1-hydroxybenzotriazole (HBz), found to have the least inhibiting ability of all the compounds throughout the experiment, inhibited the nitrification of urea-N in the north soil by $30 \%$ during the first week. It is not clear if the observed rates represent the real inhibition capabilities of Bz derivatives because of the full nitrification of the urea-N control. At two weeks, the urea-N control was at

Table 2. Nitrification inhibition by benzotriazole derivatives (\%).

\begin{tabular}{|c|c|c|c|c|c|}
\hline Soil Type & Treatment & Week 1 & Week 2 & Week 3 & Week 4 \\
\hline North & Urea & 0 & 0 & 0 & --- \\
\hline North & $\mathrm{Bz}$ & 40.8 & 20.4 & 5.2 & --- \\
\hline North & $\mathrm{CBz}$ & 30.2 & 1.5 & 6.8 & --- \\
\hline North & $\mathrm{HBz}$ & 27.7 & -5.8 & 9.7 & --- \\
\hline North & $\mathrm{MBz}$ & 38.0 & 11.3 & 7.3 & --- \\
\hline South & Urea & 0.0 & 0.0 & 0.0 & -- \\
\hline South & $\mathrm{Bz}$ & 52.4 & 38.8 & 4.7 & --- \\
\hline South & $\mathrm{CBz}$ & 38.0 & 15.6 & 2.3 & --- \\
\hline South & $\mathrm{HBz}$ & 1.6 & -0.4 & -5.9 & --- \\
\hline South & $\mathrm{MBz}$ & 46.1 & 20.4 & 1.1 & --- \\
\hline $\begin{array}{l}\text { Manhattan } \\
\text { Pile }\end{array}$ & Urea & 0.0 & 0.0 & 0.0 & 0.0 \\
\hline $\begin{array}{l}\text { Manhattan } \\
\text { Pile }\end{array}$ & $\mathrm{Bz}$ & 29.2 & 34.8 & 24.6 & 26.6 \\
\hline $\begin{array}{l}\text { Manhattan } \\
\text { Pile }\end{array}$ & $\mathrm{CBz}$ & 15.3 & 22.2 & 41.5 & 47.4 \\
\hline $\begin{array}{l}\text { Manhattan } \\
\text { Pile }\end{array}$ & $\mathrm{HBz}$ & 9.0 & 16.7 & 17.3 & 25.1 \\
\hline River Bank & Urea & 0.0 & 0.0 & 0.0 & 0.0 \\
\hline River Bank & $\mathrm{Bz}$ & 55.6 & 90.3 & 89.9 & 92.2 \\
\hline River Bank & $\mathrm{CBz}$ & 53.2 & 90.1 & 89.0 & 89.9 \\
\hline River Bank & $\mathrm{HBz}$ & 50.0 & 84.0 & 74.1 & 62.8 \\
\hline River Bank & $\mathrm{MBz}$ & 54.8 & 90.9 & 90.1 & 89.9 \\
\hline
\end{tabular}




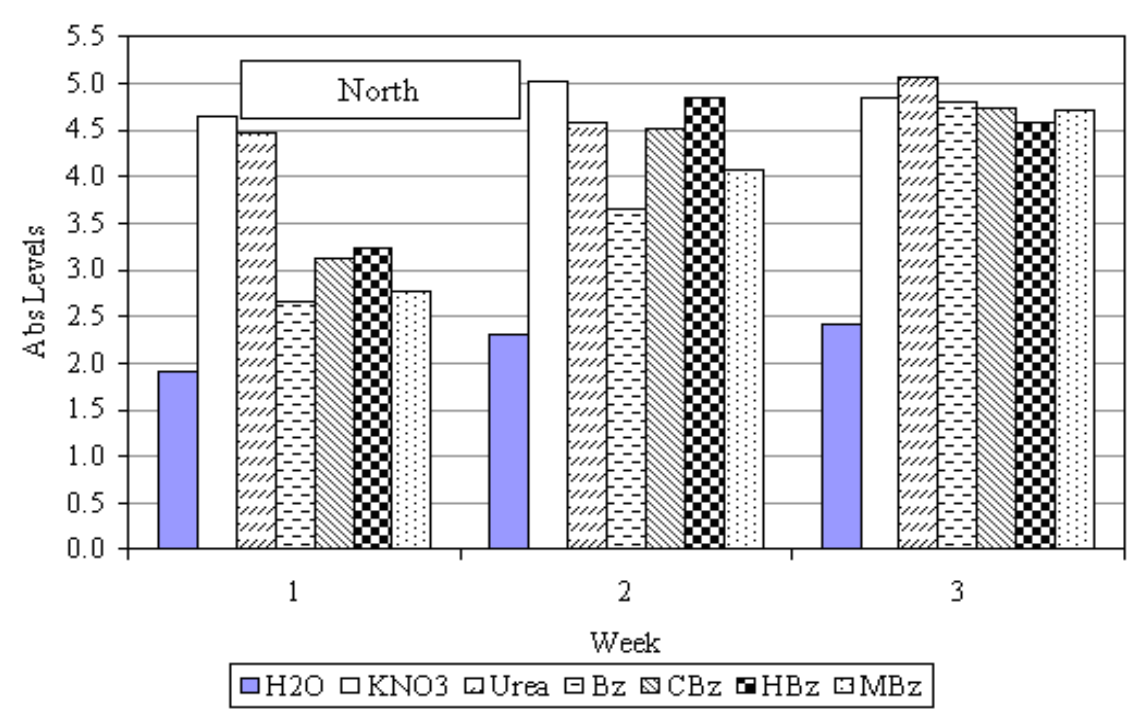

Figure 2. Soil from the north side of the Kansas River. Treatments and times are indicated on the figure itself. See Materials and Methods for details of treatments. Vertical axis represents equivalent absorbance of the undiluted soil. The equivalent absorbance of $100 \mathrm{mg} / \mathrm{L} \mathrm{N}$ is 2.64 on this scale.

a level of $174 \mathrm{mg} / \mathrm{L}$ while the concentration of the nitrate control was $190 \mathrm{mg} / \mathrm{L}$. During the second week, inhibition by the test compounds was considerably less than the week before. The trends are consistent in showing that Bz and MBz have the ability to inhibit nitrification of urea-N more effectively than CBz and HBz. The third week of analysis of the north soil shows that differences between treatments are small. In the north soil, it appears there is a large population of bacteria in the soil equipped for the task of converting ammonia to nitrate. In all cases, even with the presence of the test compounds, the urea- $\mathrm{N}$ fertilizer was completely transformed into nitrate- $\mathrm{N}$ by the third week. This could also be related to the large amount of nitrate-N already present in the soil. The level of nitrate-N present without the addition of urea-N fertilizer or potassium nitrate was measured for the three-week period in the $\mathrm{H}_{2} \mathrm{O}$ control. Values were $72 \mathrm{mg} / \mathrm{L}$ in the first week, $87 \mathrm{mg} / \mathrm{L}$ in the second week, and $92 \mathrm{mg} / \mathrm{L}$ in the third week (see Figure 2). The slight increase in nitrate concentration over the three-week period in the water control could possibly indicate pre-existing ammonia or biomass $\mathrm{N}$, which was converted upon moistening the air-dry soil. This high and changing background of nitrate complicates interpretation of the nitrification inhibition data, resulting in underestimation of the efficacy of the inhibitors. 


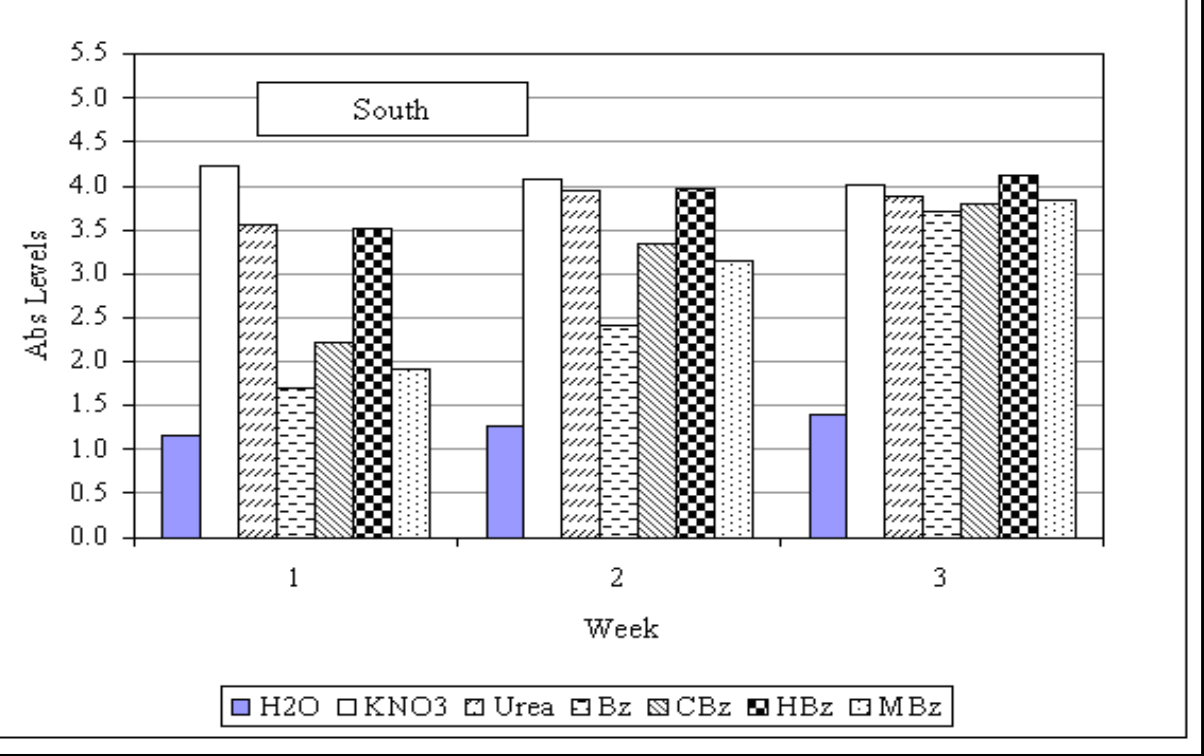

Figure 3. Soil from the south side of the Kansas River. Treatments and times are indicated on the figure itself. See Materials and Methods for details of treatments and Figure 2 for explanation of vertical scale.

The south soil had many properties similar to the north soil. Like the north soil, the south soil reached nearly complete nitrification of urea-N in the first week (Figure 3). The nitrate concentration of the urea-N control at the end of the first week was $135 \mathrm{mg} / \mathrm{L}$, while the nitrate control was 160 $\mathrm{mg} / \mathrm{L}$, indicating about $85 \%$ of full nitrification. As in the north soil, the $\mathrm{HBz}$ had little effect on the nitrification inhibition. Bz again had the largest inhibition (52\%), followed by MBz and CBz. The $\mathrm{H}_{2} \mathrm{O}$ control of the south soil behaved similarly to the $\mathrm{H}_{2} \mathrm{O}$ control of the north soil. Each week it slightly increased in its nitrate-N, from $44 \mathrm{mg} / \mathrm{L}$ after one week to $53 \mathrm{mg} / \mathrm{L}$ after three weeks. During the second week, the relative efficacy of inhibition remained in the same order as for week one. There was little inhibition evident in the third week.

The Manhattan pile soil behaved rather differently from the north and south soils in terms of the rate of nitrification (see Figure 4). By the end of the first week, the urea-N control was only at a concentration of $38 \mathrm{mg} / \mathrm{L}$, while the nitrate control was at $166 \mathrm{mg} / \mathrm{L}$, and the water control was 35 mg/L. During the second week, the Manhattan pile soil went from $22 \%$ to $33 \%$ nitrification in comparison to the nitrate control, which was at $158 \mathrm{mg} / \mathrm{L}$. By the third week, the level reached 43 $\%$ and by the fourth week it was $54 \%$ nitrified, in comparison to the nitrate control. The $\mathrm{H}_{2} \mathrm{O}$ 


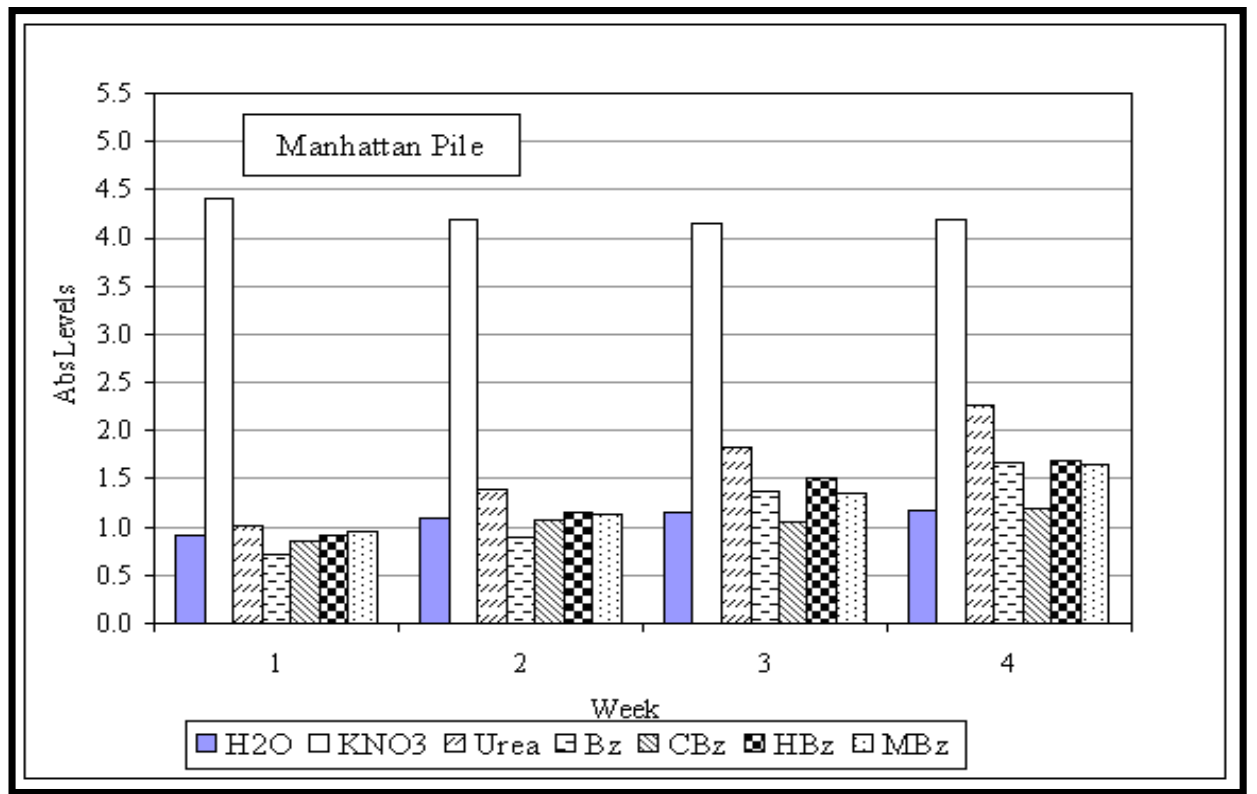

Figure 4. Soil from the Manhattan storage pile. Treatments and times are indicated on the figure itself. See Materials and Methods for details of treatments and Figure 2 for explanation of vertical scale.

control had similar nitrate-N levels as the south soil, starting with a concentration of $35 \mathrm{mg} / \mathrm{L}$ and going up slightly to $44 \mathrm{mg} / \mathrm{L}$. Overall, the Manhattan pile soil had a low nitrification rate. It would have been interesting to examine the samples for the Manhattan pile until the urea-N control reached full nitrification of the urea fertilizer, but the relative inhibition pattern generally was constant over the four-week testing period.

Like the Manhattan pile soil, the river bank samples were also tested for four weeks because of the slow nitrification rates of the test samples. The test compounds inhibited the nitrification of urea-N best in the river bank soil samples (see Figure 5). After the first week, the urea-N control was only nitrified to a concentration of $33 \mathrm{mg} / \mathrm{L}, 23 \%$ relative to the nitrate control at $143 \mathrm{mg} / \mathrm{L}$. All of the test compounds inhibited the rate of nitrification by at least 50\%. Levels of nitrate found with the test compound samples were even less than the concentration of the $\mathrm{H}_{2} \mathrm{O}$ control $(18 \mathrm{mg} / \mathrm{L})$. By the second week, the urea-N control had jumped to $95 \%$ of the nitrate control. At three weeks, there was essentially $100 \%$ nitrification with a concentration of $147 \mathrm{mg} / \mathrm{L}$. Concentrations of nitrate-N were still lower than the $\mathrm{H}_{2} \mathrm{O}$ control $(22 \mathrm{mg} / \mathrm{L})$ in the cases of Bz, CBz, and MBz. Even at four weeks, these compounds kept concentrations of nitrate- $\mathrm{N}$ lower than the $\mathrm{H}_{2} \mathrm{O}$ control (22 mg/L). 


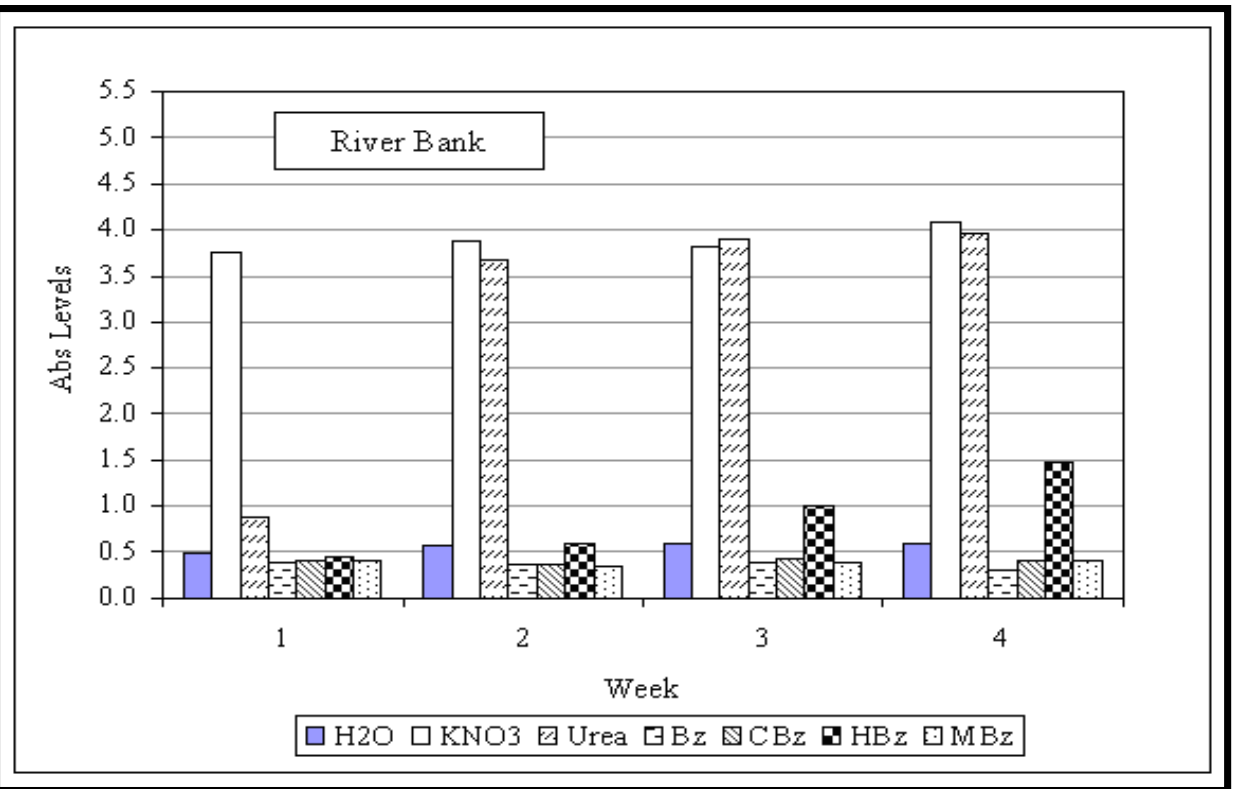

Figure 5. Soil from the bank of the Kansas River. Treatments and times are indicated on the figure itself. See Materials and Methods for details of treatments and Figure 2 for explanation of vertical scale.

It is unclear what an average nitrification inhibition percent would be for an average soil, given the variation between soils. The makeup of the soils (specifically \% O.M.) greatly affects the inhibitory strength of the compounds. The north soil had the highest organic matter (2.3\%), and the compounds had the least effect in inhibiting the nitrification of the urea fertilizer. The effect of the test compounds in the river bank soil was the greatest, while organic matter level in the river bank soil was the lowest (0.3\%). It was mainly sand (54\%). It appears that the benzotriazoles bind to the organic matter, decreasing the amount available to inhibit nitrification. Even the Manhattan pile soil shows this trend, where although the initial rate of nitrification is relatively slow compared to the other soils, the inhibition percents are low. The Manhattan pile also has the second largest percent of organic matter (2.1\%). There is also another aspect of the Manhattan pile soil that makes it unique and possibly accounts for the slow nitrification rate of the soil. The $\mathrm{pH}$ of the Manhattan pile soil (6) is the lowest by a considerable amount. This low pH level could indicate inactivity of bacteria in the soil responsible for the nitrification of ammonia.

Another very important point is the trend in potency of the inhibition. It is clear that $\mathrm{HBz}$ has little effect on the nitrification of urea-N. Consistently, Bz has the greatest effect, where MBz has the 
second greatest effect, and CBz has the least effect of the three. On a molar concentration basis, there is more Bz per mass of soil than MBz or CBz, because all treatments used the same weight ratio of inhibitor to supplied N (1:10). The formula weight of CBz is $153.5 \mathrm{~g} / \mathrm{mol}$, while Bz is $119 \mathrm{~g} /$ mol, a 32.5\% difference. Thus the greater inhibition effect of Bz may simply indicate it was present at a higher concentration, not that it is a more effective inhibitor.

This study was undertaken as an exploratory study. Thus, we gave up some statistical power of conventional replications in favor of examining a wider range of variables. Inspection of the results for the samples drawn at different times for a single soil with added nitrate indicates that the analytical method was highly reproducible. In all four figures, the measured nitrate level is reproducible within $+/-4 \%$ of the average measured value over time ( $n=3$ or 4$)$. At the low end of the range, nitrate levels in the river bank soil treated with each of the benzotriazoles except $\mathrm{HBz}$ vary no more than $+/-10 \%$ of the measured value. Of course the absolute error is much smaller for these lower numbers. Similarly, it is apparent for all but the Manhattan pile soil that addition of urea$\mathrm{N}$ gives the same result as addition of nitrate- $\mathrm{N}$ by week 3 , within a few percent.

One purpose of this research was to determine if benzotriazole (Bz) and its derivatives, such as 5-chlorobenzotriazole (CBz), 1-hydroxybenzotriazole (HBz), and 5-methyl-1H-benzotriazole (MBz) could be used as nitrification inhibitors for fertilizers to increase their effectiveness and reduce the leaching of nitrate- $\mathrm{N}$ in temperate agricultural soils. All compounds have some inhibitory capabilities. Even $\mathrm{HBz}$ inhibited the nitrification of urea-N in some soils. The compounds $\mathrm{Bz}, \mathrm{MBz}$, and CBz were found to have significant nitrification inhibition in all soil types. Even in the extremely active north soil, all three effectively inhibited nitrification in the first week. In the instance of the low O.M. river bank soil, all three inhibited the nitrification completely for four weeks. That soil also showed a slower rate of conversion of urea- $\mathrm{N}$ to nitrate- $\mathrm{N}$ than did the north and south soils.

Puttanna et al. (1999, 2001a,b) tested Bz in comparison with the highly effective dicyandiamide, as well as o-nitrophenol and $m$-nitroaniline, both in laboratory and field settings. In a laboratory test with those inhibitors and others at $10 \mathrm{mg} / \mathrm{kg}$ soil and urea- $\mathrm{N}$ at $100 \mathrm{mg} / \mathrm{kg}$, the relative potency of inhibition differed over time of a 45-day study. Some of the compounds, such as 
dicyandiamide, were likely broken down after a lag phase. Only the Bz appeared to maintain relatively good inhibition of nitrification in its soils. In a field setting where the inhibitor was applied at a constant ratio of 1:10 with urea-N, up to $450 \mathrm{~kg} / \mathrm{ha}$ per season (as $\mathrm{N}$ ), Bz was the most effective inhibitor of the four tested. The field test soil was 65\% sand with a pH of 6.4 (O.M. not specified) and so might be more favorable for inhibition than a higher $\mathrm{pH}$ soil with high O.M. The laboratory test soil had a pH of 8.3 and $0.6 \%$ organic $\mathrm{C}$ with $78 \%$ sand (Puttanna et al., 1999).

The mechanism whereby benzotriazoles inhibit nitrification remains unknown (McCarty, 1999). The work of McCarty and Bremner (1989) indicated that unsubstituted heterocyclic compounds with two adjacent $\mathrm{N}$ atoms are effective, whereas those with nonadjacent $\mathrm{N}$ atoms are not. Among substituted heterocycles, 2-chloro-6-(trichloromethyl)pyridine (nitrapyrin) is one of the most effective. It is commercially available as $\mathrm{N}$-Serve. Nitrapyrin at $0.01 \mathrm{mmol} / \mathrm{kg}$ showed the same potency of inhibition as Bz at $0.1 \mathrm{mmol} / \mathrm{kg}$ in three different soils (McCarty and Bremner, 1989). Thus, relative cost for equivalent inhibition in a field setting would depend on ease of synthesis of the compounds from cheap precursors. A few other compounds, such as dicyandiamide, have been applied in field studies as nitrification inhibitors, but a literature search indicates that nitrapyrin is the predominant agent in use.

The most likely site of inhibition of nitrification is the enzyme ammonia monooxygenase. It has not been isolated in a pure form, so it is not readily accessible for detailed study, but McCarty (1999) lists nitrapyrin, along with over 50 other compounds, as a substrate of that enzyme. At our suggestion, Dr. Andy Pacheco tested benzotriazole as a potential inhibitor of hydroxylamine oxidase, the second enzyme in the pathway of nitrification. He showed, using purified enzyme, that benzotriazole is not an inhibitor at millimolar concentrations (personal communication, July 26, 2002). Thus the inhibition is most likely a direct or indirect effect on the ammonia monooxygenase. Because nitrapyrin is a substrate for the ammonia monooxygenase system, it may be decomposed within a relatively short time in the soil by nitrifiers, as well as being attacked by other bacteria. Reported half-lives are 5-42 days (Wolt, 2000). Nitrapyrin is also slightly volatile and a portion may be lost by volatilization, particularly from dry soils (Wolt, 2000). 
There is no evidence that benzotriazole can be decomposed by microbes in soil. This may make it a more effective nitrification inhibitor, but could lead to toxic reactions with other systems. Based on its Henry's constant, Bz is about 30x less likely to be lost by volatilization than is nitrapyrin.

Benzotriazole is not simply a potent general inhibitor of microbial growth. According to results summarized by the EPA(USEPA, 1977), concentrations of $20 \mathrm{mg} / \mathrm{L}$ in solution are needed for significant growth inhibition of common microorganisms. For some test systems, depending on the microbial species, 50\% inhibition required $>\mathrm{g} / \mathrm{L}$ amounts. See also the results of Gruden et al. (2001) discussed below. If the site of inhibition is ammonia monooxygenase, it is likely that methane monooxygenase is also a target for inhibition by this compound, so that methanotrophic organisms, in addition to nitrifiers, may be selectively inhibited. That is the case for nitrapyrin (Topp and Knowles, 1984), but there are no reports for benzotriazoles.

It is unclear how the observed nitrification inhibition relates to environmental releases of aircraft deicing fluids (ADFs). Soil concentrations attained by land application of the ADFs may reach levels studied here, even when fairly small quantities of ADF are applied to the soil. The dosage used in these studies was $10 \mathrm{mg} / \mathrm{kg}$ soil, which would correspond to about $10 \mathrm{~mL}$ ADF/kg soil using ADF as applied to aircraft, with $20 \%$ glycol in the ADF solution, containing $0.5 \%$ by weight of Bz per weight of glycol, which is a typical composition (Castro et al., 2001). Thus a single spill could inhibit nitrification in soil around a runway.

We have applied diluted pure glycol solution at levels of $5 \mathrm{~g} / \mathrm{L}$ to soil for months without toxicity to grass. It would take 400 such applications ( $400 \mathrm{~d}$ ) to result in a cumulative dose of 10 $\mathrm{mg} \mathrm{Bz} / \mathrm{kg}$ soil, if it were present at the indicated ratio of $0.5 \%$ by weight relative to the glycol. Applying stored deicer solution from detention ponds over one or two seasons could yield this level of accumulation, even when diluted, so that glycol toxicity to soil (anaerobiosis) was avoided.

Mixing of ADFs with other waste streams, as is done when they pass to a municipal waste treatment plant, could result in inhibition of nitrification, methanogenesis, or other processes. The extent to which this might occur would presumably depend on the organic matter content of the waste. Gruden et al. (2001) showed significant inhibition of methane production in an anaerobic 
digester at levels of $\mathrm{MBz}$ above $300 \mathrm{mg} / \mathrm{L}$, which corresponds to about 1/3 the concentration applied to aircraft (20\% glycol with 1:200 MBz:glycol). Some of the MBz may have been sorbed to organic matter in the reactor.

There are no published reports on studies of benzotriazole toxicity in aerobic waste treatment systems. Work cited by the EPA(USEPA, 1977) indicates no inhibition of survival of organisms isolated from aerobic treatment systems at concentrations of $\mathrm{Bz}$ up to $13 \mathrm{mg} / \mathrm{L}$, but some decrease in survival for tolyltriazole (mixed isomers of 4- and 5- methylBz) at $20 \mathrm{mg} / \mathrm{L}$. The organisms may be more resistant in situ where there is a large amount of organic matter present to sorb the benzotriazole.

In the absence of proven pathways for degradation of the benzotriazoles, their application to soil is problematic. The experiments cited, where it has been tested under field conditions, are in another country not under the same regulations that apply in the U.S. It is evident from the present work and that of Puttanna et al. (1999, 2001a,b) that inhibition of nitrification can occur if the benzotriazoles reach a critical concentration dependent on the soil organic matter content. It is also clearly established that benzotriazoles are toxic to plants and other organisms at higher concentrations, in the range of 10-50 mg/L solution (Cornell et al., 2000; Castro et al., 2001). If the average soil water content is $20 \%$ by weight, a dosage of $10 \mathrm{mg} / \mathrm{kg}$ corresponds to $50 \mathrm{mg} / \mathrm{L}$ in the aqueous phase for a soil with zero O.M. Thus with even a single application of the nitrification inhibitor, significant growth inhibition may be observed in plants growing in sand, unless they are able to detoxify it. Fortunately, it appears that higher plants are able to do so (Castro et al., 2001). Soils with high O.M. will show less growth inhibition. Hart et al (in preparation) have determined the sorption properties of soils studied here for each of the benzotriazoles. Knowing the sorption coefficient, it is possible to predict the available benzotriazole in the aqueous phase, and hence the likely extent of toxicity to plants in natural soils. Those results will appear in a separate publication.

Data is lacking on the capabilities of aquatic organisms to degrade or detoxify the benzotriazoles. It appears that during ADF treatments currently being used, dilution is the only attempted solution of the pollution problem. Clearly more needs to be done to manage these common contaminants. 


\section{ACKNOWLEDGMENTS}

This research was partially supported by the U.S. E.P.A. and the U.S Air Force under assistance agreements R-819653, R-825549, and R-825550 to the Great Plains-Rocky Mountain Hazardous Substance Research Center for regions 7 and 8 under projects $94-27$ and 98-3. It has not been submitted to the EPA for peer review and, therefore, may not necessarily reflect views of the agency and no official endorsement should be inferred. The Center for Hazardous Substance Research also provided partial funding. This research was partially supported by the Kansas State University Biochemistry Department and Wamego High School Science Department. The science department at Wamego High School provided many of the instruments used in the experimentation. They are thanked for that use. Sigifredo Castro-Diaz is thanked for assistance with figure production. Andy Pacheco is thanked for testing the effect of benzotriazole on hydroxylamine oxidase.

\section{REFERENCES}

Bundy, L.G., and J.M. Bremner, 1973. Inhibition of nitrification in soils. Soil Sci. Soc. Am. Proc., 37, pp. 396-398.

Call, H.P., and I. Mucke, 1997. History, overview, and applications of mediated ligninolytic systems, especially laccase-mediator systems (lignozyme process). J. Biotechnol., 53, pp. 163202.

Castro, S., L.C. Davis, and L.E. Erickson, 2001. Plant-enhanced remediation of glycol-based aircraft deicing fluids. Practice Periodical of Hazardous, Toxic, and Radioactive Waste Management, July 2001, pp. 141-152.

Cornell, J.S., D.A. Pillard, and M. T. Hernandez, 2000. Comparative measures of the toxicity of component chemicals in aircraft deicing fluid. Environ. Toxicol. Chem., 19, pp. 1465-1472.

Gruden, C.L., S.M. Dow, and M.T. Hernandez, 2001. Fate and toxicity of aircraft deicing fluid additives through anaerobic digestion. Water Environ. Res., 73, pp 72-79.

McCarty, G.W., and J.M. Bremner, 1989. Inhibition of nitrification in soils by heterocyclic nitrogen compounds. Biol. Fertil. Soils, 8, pp. 204-211.

McCarty, G.W., 1999. Modes of action of nitrification of inhibitors. Biol. Fertil. Soils, 29, pp. 1-9.

Pillard, D.A., 1995. Comparative toxicity of formulated glycol deicers and pure ethylene and propylene glycol to Ceriodaphnia dubia and Pimephales promelas. Environ. Toxicol. Chem., 14, pp. 311-315.

Puttanna, K., N.M. Nanje Gowda, and E.V.S Prakasa Rao, 1999. Evaluation of nitrification inhibitors for use under tropical conditions. Commun. Soil Sci. Plant Anal., 30(3\&4), pp. 519-524. 
Puttanna, K., N.M. Nanje Gowda, and E.V. S. Prakasa Rao, 2001a. Effects of applications of N fertilizers and nitrification inhibitors on dry matter and essential oil yields of Java citronella (Cymbopogon winterianus Jowitt). J. Agric. Sci., 136, pp 427-431.

Puttanna, K., N.M. Nanje Gowda, and E.V.S. Prakasa Rao, 2001b. Regulation of nitrification by benzotriazole, $o$-nitrophenol, $m$-nitroaniline and dicyandiamide, and pattern of $\mathrm{NH}_{3}$ emissions from citronella field fertilized with urea. Water, Air and Soil Pollution, 131, pp 11-17.

Rollinson, G., and A.G. Callely, 1986. No evidence for the biodegradation of benzotriazole by elective culture or continuous enrichment. Biotech. Lett. 8, pp. 303-304.

Topp, E., and R. Knowles, 1984. Effects of nitrapyrin [2-chloro-6-(trichloromethyl)pyridine] on the obligate methanotroph Methylosinus trichosporium )B3b. Appl. Environ. Microbiol. 47, pp 258-262.

USEPA, 1977. Investigation of selected potential environmental contaminants: benzotriazoles. USEPA 560/2-77-001.

Wolt, J.D., 2000. Nitrapyrin behavior in soils and environmental considerations. J. Environ. Qual., 29, pp 367-379. 